\title{
Designing a proposal review process to facilitate interdisciplinary research
}

\author{
Kazuyoshi Shimada, Mitsuo Akagi, Tohru Kazamaki and \\ Shinichi Kobayashi
}

\begin{abstract}
This paper introduces a novel proposal review process to facilitate interdisciplinary research. This method provides not only for competition for a grant, but also for collaboration among applicants. Applicants can refine their research proposals through a workshop discussion held during the proposal review process. This presents an opportunity for applicants to obtain feedback based on a broad range of viewpoints from people with various expertise. The method has actually been applied to the proposal review process in science and engineering fields (Takeda Techno-Entrepreneurship Award, 2001, 2002). Its feasibility and some of the merits found are discussed.
\end{abstract}

$\mathrm{T}$ HE OBJECTIVE of this paper is to find and to propose a new method to facilitate interdisciplinary research in terms of the proposal review process.

Social needs for interdisciplinary ${ }^{1}$ research aiming to solve joint problems in science, technology and society have been increasing. In 1994, Gibbons et al found a new "mode" of knowledge production scheme in response to the social needs in contemporary societies (Gibbons, 1994). In 2005, the National Academies in the USA pointed out that science and engineering research continually evolves beyond the boundaries of single disciplines and offers employment opportunities that require not only depth of knowledge, but also integration, synthesis and an array of skills (National Academies, 2005). In 2004, the European Union Research Advisory Board (EURAB) stated some problems in developing

\footnotetext{
Kazuyoshi Shimada, Mitsuo Akagi and Tohru Kazamaki are at the Takeda Foundation, St. Lukes Tower 31F, 8-1 Akashicho, Chuo-ku, Tokyo 104-6591, Japan; Email: smd@ takeda-foundation.jp. Shinichi Kobayashi is at the Research Center for University Studies, University of Tsukuba, 3-29-1 Ootuka, Bunkyo-ku, Tokyo 112-0012, Japan.

The authors cordially acknowledge Dr Ikuo Takeda for his private donation to found such an innovative award system, and gratefully acknowledge Mrs Margaret D Ohto for critical proofreading.
}

interdisciplinary research and showed a number of levels at which problems should be tackled (EURAB, 2004). In 2005, the Council for Science and Technology Policy in Japan announced a promotion of $R \& D$ activities relating to the type of science and technology for the interdisciplinary resolution of issues (Council for Science and Technology Policy, Japan, 2005). Behind these approaches, there are strong expectations for science and technology to address an increasing number of issues in society, for example international terrorist attacks; proliferation of weapons of mass destruction; large-scale accidents and natural disasters; crimes committed through computer networks; and emerging or reemerging infectious diseases. Most of the issues faced by society are complicated and a singledisciplinary approach to them is inadequate. Therefore, interdisciplinary research is required.

Despite many trials, ${ }^{2}$ it is difficult to facilitate interdisciplinary research because pathways for knowledge production and accumulation have been developed individually in the traditional disciplines. In order to bridge the gap between interdisciplinary activities and conventional disciplinary activities, we attempted to add a new device to the procedures for a conventional 'grant review'. Here we introduce a proposal review process that can be incorporated into the grant review process. For the first time, we have positioned the proposal review process as a knowledge production process, and designed a novel 
process that will facilitate interdisciplinary research. In this paper, we introduce this proposal review process and review its feasibility based on the results of its implementation.

\section{Design of the proposal review process}

The roles of the proposal review are first to decide grant allocation and second to review and critique the research proposal objectively. During the review and critique process, requirements from outside the discipline can be worked into the research proposal. The grant that will be allocated to the research provides an incentive for many participants from various disciplines. These intrinsic parts of the proposal review process are favorable for facilitating interdisciplinary research.

By taking advantage of these merits, we designed a concrete proposal review process. The new proposal review process was designed for the selection of the recipients of the Takeda TechnoEntrepreneurship Award (TTEA ${ }^{3}$ ), an award for research proposals in the science and technology fields. The review process for the TTEA scheme consists of two stages. The first stage is a review of the funding sector ${ }^{4}$ itself; the second stage is the research proposal review for grant selection. In the first stage, we call for sector proposals for which research grants should be allocated, and select six sectors. Then we call for research proposals related to those six sectors. The first stage is noteworthy for examining problems from outside the discipline. While the function of the first stage merits discussion, this article will focus on a discussion of the "second stage" of the proposal review process.

The newly designed proposal review process has the following three main features: first it is an interactive review process; second it is a review process that is open to all applicants; and third it is a review process that is conducted on the World Wide Web.

\section{Interactive review process}

We decided to carry out an interactive review process for the research proposals. An interactive review enables information exchange between reviewers and applicants during the review process. In the interactive evaluation, reviewers can ask questions of the applicants directly and obtain information to help in their selection. They also can express their concerns precisely about the selection criteria (concept of the award) through questions and answers (Q\&A). In this way, applicants can be made aware of the reviewing criteria based on a series of interactions. They can revise their research proposals during the reviewing process in order to impress more effectively with the crucial advantages of their proposals. The interactions offer opportunities to obtain new knowledge that will contribute to the future development of their research. Therefore, we consider that this review process can facilitate the interdisciplinarity of research appropriately.

On the other hand, compared with the conventional review process, the "interactive" process places a greater workload on both applicants and reviewers (Table 1).

\section{A review process that is open to all applicants}

Interactions during the review process are disclosed not only between an applicant and a reviewer, but also among all applicants and all reviewers. Here "open" means the disclosure of the research proposals and all interactions in the review process to all applicants to provide an opportunity for discussion. It is not the disclosure of the entire process to persons who have no relationship to the review process. We opened the review process only to authorized persons (eg applicants and reviewers). When we regard the proposal review process as an interdisciplinary knowledge production process, disclosure of the review process among the participants is necessary because they cannot interact effectively without knowledge of each proposal. Interdisciplinary research has to be developed through continuous and mutual revision of proposed ideas. (Here, we made a rule that intellectual property rights had to be managed by the applicants in a responsible manner.)

Our review process raises expectations in the applicants that are not provided by the conventional review process. In the conventional review process, applicants prepare documents for the application and post them, and the reviewers read the documents and judge them for grant allocation. Usually there are no direct interactions between applicants and reviewers. Through our process, applicants have the chance to learn more by encountering the research proposals of other applicants. They can discuss with other applicants who have different perspectives. They also get the chance to build a new human network that may trigger research collaborations. These expectations may provide incentives to the applicants.

Disclosure of the review process increases the fairness of the final decisions, which is a merit for

Table 1. Merits and demerits of interactivity for participants in the cyber workshop

\begin{tabular}{|c|c|c|}
\hline & Applicants & Reviewers \\
\hline \multirow[t]{2}{*}{ Merits } & $\begin{array}{l}\text { They can revise their } \\
\text { research proposals } \\
\text { during the reviewing } \\
\text { process }\end{array}$ & $\begin{array}{l}\text { - They can ask applicants } \\
\text { questions directly and } \\
\text { get information to help } \\
\text { in their selection }\end{array}$ \\
\hline & $\begin{array}{l}\text { - They can stress } \\
\text { effectively the crucial } \\
\text { advantages of their } \\
\text { proposals }\end{array}$ & $\begin{array}{l}\text { They can express their } \\
\text { concerns precisely } \\
\text { about the selection } \\
\text { criteria (concept of the } \\
\text { award) through Q\&A }\end{array}$ \\
\hline Demerits & - Large workload & - Large workload \\
\hline
\end{tabular}


Table 2. Merits and demerits of an open review process for participants in the cyber workshop

\begin{tabular}{|c|c|c|}
\hline & Applicants & Reviewers \\
\hline \multirow[t]{2}{*}{ Merits } & $\begin{array}{l}\text { - They can discuss with } \\
\text { other applicants who } \\
\text { have different } \\
\text { perspectives }\end{array}$ & $\begin{array}{l}\text { There is increased } \\
\text { fairness of decisions }\end{array}$ \\
\hline & $\begin{array}{l}\text { - They get a chance to } \\
\text { build a new human } \\
\text { network }\end{array}$ & \\
\hline Demerits & $\begin{array}{l}\text { - Large workload } \\
\text { - There are risks that } \\
\text { other applicants may } \\
\text { steal ideas }\end{array}$ & - Large workload \\
\hline
\end{tabular}

reviewers. It is easier for applicants to consider the decisions transparent.

On the other hand, there are risks that other applicants may steal ideas. However, we have noticed that it is not only the first publication of a piece of new knowledge, but also collaboration (eg sharing new findings produced by connecting each piece of knowledge, discovering a new field to which that knowledge can be applied, or building personal networks) that is critical for the promotion of research, especially in engineering research fields. Therefore, we considered that applicants would recognize the merits of disclosure and accept the risks in order to enjoy the benefits of the "open" review process (Table 2).

\section{A review process on the World Wide Web}

There is a proposal review held during a workshop in which all applicants participate, and this workshop is held on a website. We call the workshop the "cyber workshop". It consists of a bulletin board located on the website. A poster explaining the research proposal of each applicant is placed in the cyber workshop, and discussions among applicants and reviewers are encouraged. Chairpersons, who are reviewers assigned by the selection committee, ${ }^{5}$

Table 3. Comparison of the cyber workshop with face-to-face communication

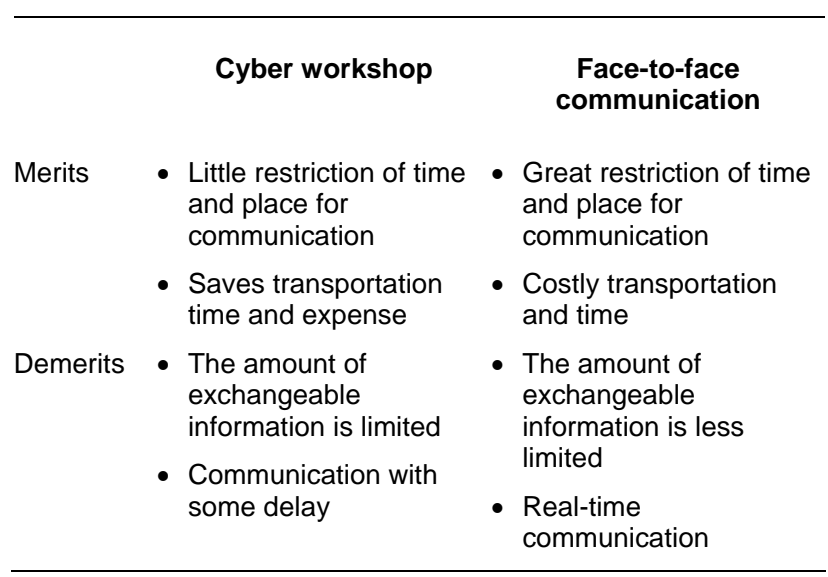

Table 4. Comparison of researcher motivation between our review process and the conventional one

\begin{tabular}{lcc} 
Researcher motivation & $\begin{array}{c}\text { Conventional } \\
\text { method }\end{array}$ & Our method \\
$\begin{array}{l}\text { Save } \\
\text { Time/load }\end{array}$ & $\checkmark$ & $\times$ \\
Get & $\checkmark$ & \\
Award money & $\times$ & $\checkmark$ \\
Knowledge & $\times$ & $\checkmark$ \\
Human network & $\times$ & $\checkmark$ \\
\hline
\end{tabular}

moderate the cyber workshop. Applicants can access the cyber workshop from their favorite place at their favorite time and submit their comments. Program officers, who are responsible for the whole award program process, check the comments in advance in order to avoid anything potentially libelous.

Operation on the Web can enhance the merits of the open review process. Once a cyber workshop is set up, participation time is not strongly restricted, and applicants can utilize their time flexibly for interactive communication. In this way, international and interdisciplinary communication can be realized smoothly. The savings realized in transportation time and expense is another merit.

This method also has its demerits. As the communication involves words and figures on a bulletin board, the amount of information exchanged is limited compared to face-to-face communication. Also, this is not real-time communication, but rather communication with some delay (Table 3).

Table 4 compares researcher motivation between our review process and the conventional one. Our method has merits in providing opportunities for acquiring new knowledge or building new human networks, even though it takes more time and the workload is greater.

Table 5 shows comparisons of features of our review process with the conventional process. In a conventional proposal review process, the review of competing applicants is hidden from applicants, and communication among applicants is impossible. The

Table 5. Comparisons of features of our review process with the conventional one

\begin{tabular}{lll}
\hline Features & \multicolumn{1}{c}{$\begin{array}{c}\text { Conventional } \\
\text { method }\end{array}$} & \multicolumn{1}{c}{ Our method } \\
$\begin{array}{l}\text { Review process of } \\
\text { other applicants }\end{array}$ & Blind & Open \\
$\begin{array}{l}\text { Communication } \\
\text { among applicants }\end{array}$ & Impossible & Encouraged \\
$\begin{array}{l}\text { Review process } \\
\begin{array}{l}\text { Revision of the } \\
\text { proposal }\end{array}\end{array}$ & Blind/unilateral & $\begin{array}{l}\text { Transparent/ } \\
\text { interactive }\end{array}$ \\
\hline
\end{tabular}


review process is also blind to the applicants themselves, and they are informed individually of the final decision of the reviewers. ${ }^{6}$ Revision of the proposal is forbidden in principle. ${ }^{7}$

By contrast, our method is remarkable in that applicants can develop their research proposals dynamically, utilizing many ideas provided by other applicants during the proposal review process.

\section{Call for research proposals and the concrete evaluation process}

Here we explain how we implemented our new method.

\section{Call for research proposals}

We called for research proposals for the Takeda Techno-Entrepreneurship Award (TTEA) from all over the world. Figure 1 shows the top page for the TTEA located on our website in 2002. We announced that the TTEA is a competition program for self-nominated research proposals, and that the selection process would be open in the cyber workshop.
We emphasized our award concepts “competition” and "collaboration". That is, the cyber workshop would be a competitive area in which the contributions of the participants would be considered part of the selection process. At the same time, however, the cyber workshop would provide a forum for collaboration among applicants. Through the call for research proposals, we announced the funding sectors (they were the same as the topics in the cyber workshop and the research proposals were loosely restricted by these sectors), appointed chairpersons of the cyber workshops (persons who had substantial knowledge of the sectors), and the monetary value of the award (10 million yen: approx. US\$80,000 ${ }^{8}$ ). Two sectors were selected in each of the three application fields (information and electronics, life science, and world environment). To encourage research proposals from abroad, all information was released in English and Japanese.

We accepted research proposals only on the Takeda Foundation website. We requested submission of electronic files of all documents for consideration by the reviewers and an A4-sized poster (an abstract of the documents) for presentation in the cyber workshop.



Figure 1. Entrance to the TTEA cyber workshop 


\section{Cyber workshop}

The cyber workshop comprised an online arena in which the research proposals were displayed. Discussions were carried out very much as in an Internet bulletin board discussion. Access to the cyber workshop required an ID and password issued by the Takeda Foundation. Only applicants, chairpersons, selection committee members and program officers were allowed access to the cyber workshop. All participants were required to state their name, organizational affiliation, position and email address clearly. This rule was intended to insure that participants in the workshops would take full responsibility for their own contributions. Applicants were encouraged to undertake active collaborations. All applicants took part in the workshop, responded to questions from the chairperson about their own proposal, and discussed the proposed research. The program officers of the Takeda Foundation checked the Q\&A submitted to the cyber workshop in order to support the chairpersons and to avoid libel. Revision of the posters was allowed during a certain period. We expected real-time improvement in the research proposals stimulated by direct feedback in the workshop discussions.

Applicants were requested to manage their own intellectual property rights with regard to information contained in the research proposals. (For example, it was suggested that patent applications be filed before publication on the workshop site.) As a lack of restrictions on confidentiality was expected to promote an open-minded atmosphere, applicants were not contractually bound to maintain confidentiality with regard to what they saw or read during the cyber workshop. Information was exchanged on condition that no confidential materials were included. We exchanged agreements that the management of the intellectual property rights was the responsibility of the applicants.

\section{Screening (selection of awardees)}

Chairpersons read the research proposals and asked applicants questions during the workshop period. Chairpersons also recommended topics for discussion with all applicants. They attempted to navigate their cyber workshop clarifying the criteria or policies of the selection. The chairpersons deepened their understanding of the research proposals during the cyber workshop and reported the abstract and features of each proposal to the selection committee. The selection committee chose the award winners taking into account the comments of the chairpersons. ${ }^{9}$

The cyber workshops were held over a period of about two months. The first-round selections and the second-round selections (finalist selections) were made on the basis of the research proposals and discussions in the cyber workshop. Selection committee interviews were held after the second-round selections. Selection committee interviews required the applicants to make a presentation before the selection committee, and to answer their questions. A telephone conference ${ }^{10}$ was used for this interview.

The selection of winners was then made based on the research proposals, cyber workshop discussions, and the review meeting of the selection committee.

\section{Results}

\section{Applicants}

There were 141 applicants in 2001 and 134 applicants in 2002. Figure 2 shows the distribution of the
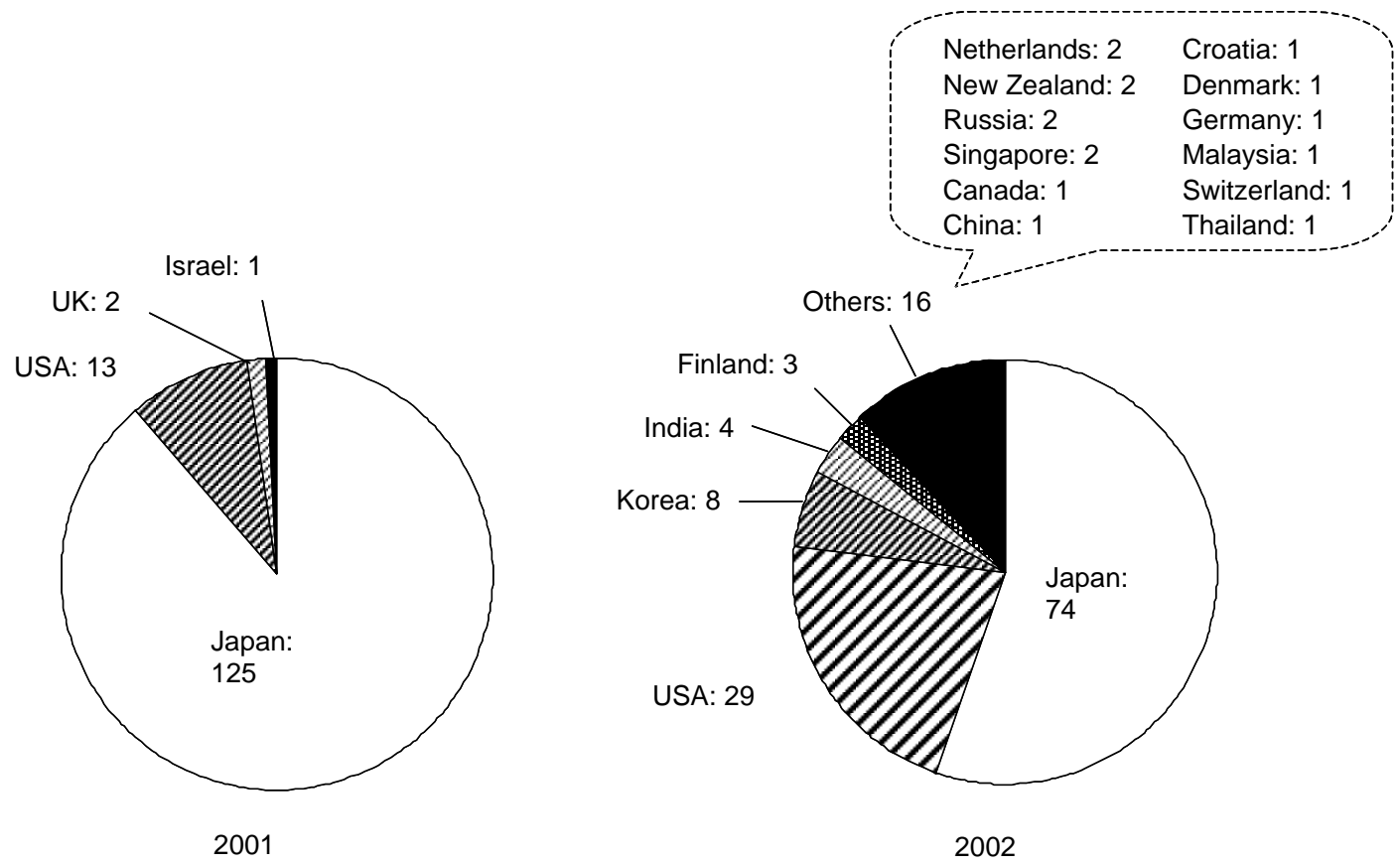

Figure 2. Distribution of the nationalities of applicants in 2001 and 2002 
Private company: 12



Private company: 15

National

institute: 29

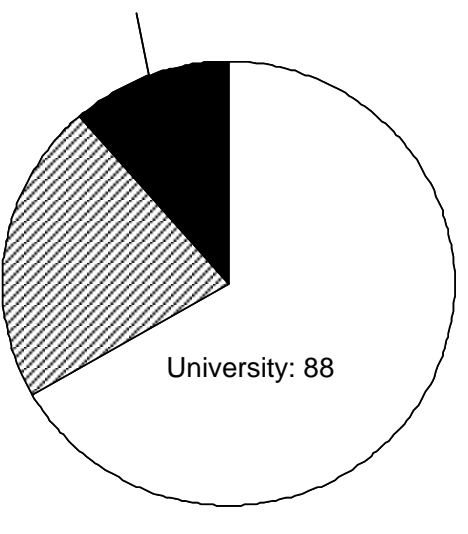

2002

Figure 3. Attributes of applicants in 2001 and 2002

nationalities of the applicants in 2001 and 2002. Due to insufficient advertisement, most of the applicants in 2001 were domestic (Japan). In 2002, better publicity of the TTEA resulted in an increase in the number of applicants from abroad.

\section{Attributes of the applicant affiliations}

Figure 3 shows the attributes of applicants. We classified their affiliations as private company, university and public research institute. A university was the most frequent affiliation. As we hoped to promote practical research, we eagerly invited researchers from private companies. However, some researchers in private companies hesitated to disclose research plans to be addressed in the future.

\section{Discussion among participants}

In order to describe the features of the cyber workshop, we counted the comments on the bulletin board and classified them into the following three categories:

1. Q\&A between chairpersons and applicants

2. Q\&A among applicants

3. Other.

Figure 4 shows the normalized number ${ }^{11}$ of comments in each workshop. The normalized number of comments indicates the mean number of comments per participant, which indicates the activity of the discussion.

In the workshops that did not come alive, most of

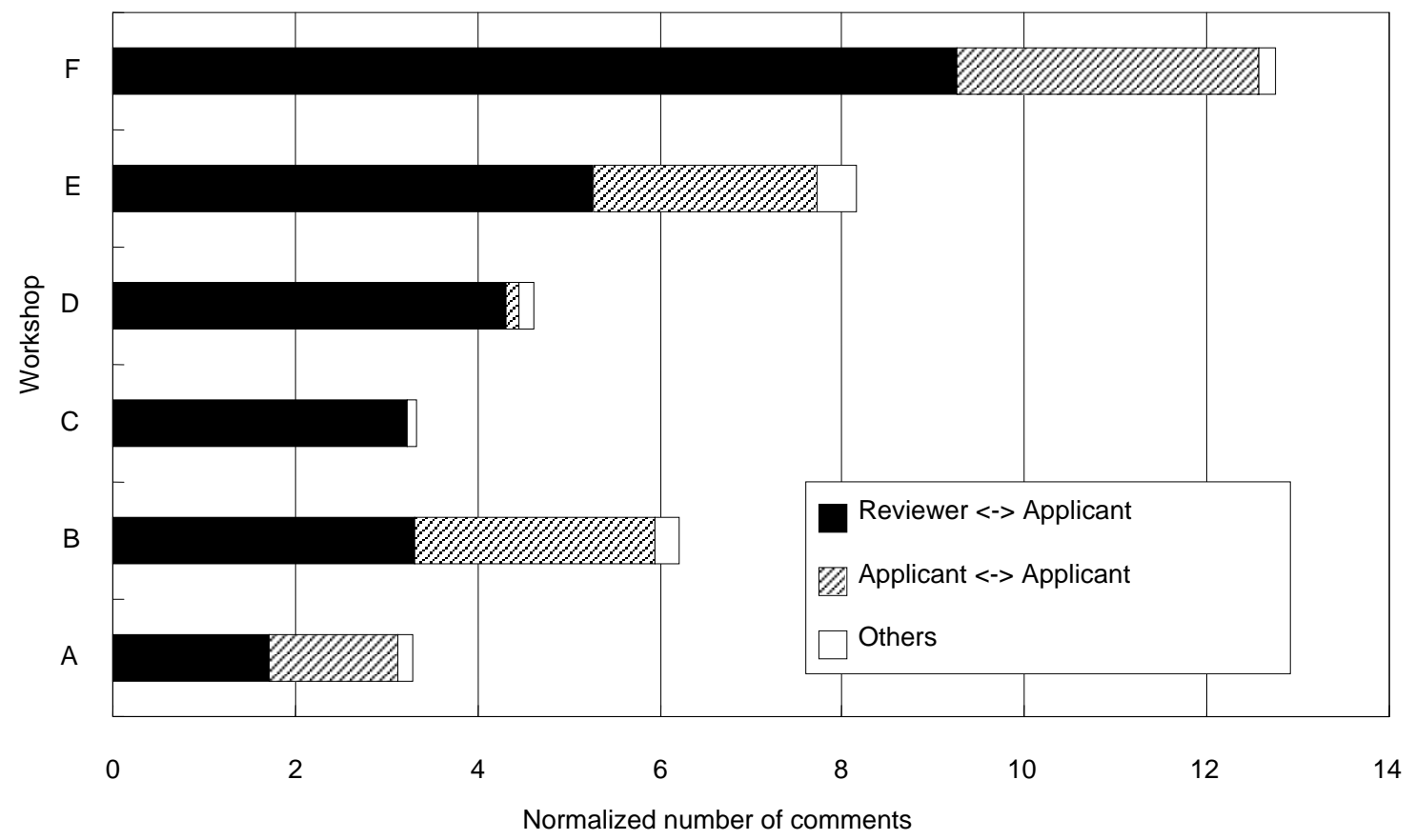

Figure 4. The normalized number of comments in each workshop 
the discussion involved questions from the chairperson and answers from the applicant to the question. This feature indicates that applicants did not participate in the workshop on their own initiative.

On the other hand, in the workshops that came alive, not only answers to the questions from the chairperson but also questions and answers among applicants accounted for a quarter to a third of the comments. This feature indicates that applicants participated and/or activated the discussion at their own initiative.

We found that most of the comments were polite, and no rancor was observed. We also found that a few key persons played important roles in the active workshops. The key persons frequently questioned the other applicants and aggressively made comments to other applicants. As a result, other applicants were encouraged to ask questions. Accurate and in-time comments from the chairpersons also played an important role in activating the discussion. The active discussions seemed to be stimulated by topics that were recognized as common issues among a broad range of expertise.

Here we show some examples of the comments:

I wish to ask all participants in this session about their view on the relative roles of software and hardware measures to enhance, possibly enforce, system reliability. My impression is that most members of our group strongly favor hardware measures - although, at least in my experience, the software components of complex systems seem more prone to cause serious problems. The problems may be due to less than satisfactory programming practices, inadvertent programming mistakes or deliberate human mischief, such as hackers. ("Question to all participants on system reliability measures" NF, 2002, Session B - Dependable Computer Systems and Secure Semiconductor Chips)

I think there are two subjects, 'understanding' and 'feeling', in public acceptance, and they are very different especially when the use of [genetically modified organisms] GMO are concerned. For example, I can explain my wife the substantial safety of the genetically engineered soybean on the market, and let her 'understand' it, but she may say "OK. You may be right, but I still don't 'feel' like it." Scientific efforts suggested by several applicants are of course very important to get public acceptance at the level of 'understanding', but I think the major difficulty of public acceptance lies in the 'feeling' matter. Since the main concern of public acceptance of environmental biotechnology is ecosystem protection, the view point of ecological study is important, and it also can provide a clue to solve this problem. "Public acceptance, understanding and feeling” HM, 2002, Session F - Environmental Biotechnology).

\section{Questionnaire}

To evaluate the performance of our method, we sent out questionnaires to all applicants and chairpersons after announcing the award winner. We did not ask specific questions but instead asked them to describe their opinions about our trial (TTEA) freely. Positive opinions and negative opinions were obtained. Here we categorize the comments from applicants as positive and negative opinions.

\section{Positive}

- The cyber workshop was a new experience and interesting for me.

- I had an enough time to consider how to answer the questions.

- It was convenient that I could participate in the cyber workshop freely in my own time.

- It was attractive especially for young researchers that the review process seemed to be promoted without restriction by discipline or organization.

- It was exciting that not just the results but proposals of research could be seen.

- The selection process was very transparent.

Negative

- Selection process was not transparent. You should disclose the selection criteria in detail.

- It was painful for me that frequent access to the cyber workshop and responses to the chairperson's questions were requested of the applicants.

- The workshop topic (sector) was too broad to make discussions with others.

- Please stimulate discussions more.

- Management of intellectual property rights was very difficult.

In addition, some thoughts of the chairpersons were as follows:

- I felt great pressure because my decisions were disclosed to all applicants.

- It was my great pleasure to receive research proposals from all over the world.

- The cyber workshop was useful in that I could accumulate information effectively in line with my selection criteria.

\section{Discussion}

\section{Was interdisciplinary research facilitated?}

A positive function to facilitate interdisciplinary research was found in our method. As shown in the above examples (discussion among applicants), comments addressing topics of social problems were frequently made, and many applicants joined in the discussion on their own initiative. Our method seems to be effective for encouraging discussion of social aspects among applicants, and this characteristic is useful for facilitating interdisciplinary research. 


\section{Our method seems to be effective for encouraging discussion of social aspects among applicants, and this characteristic is useful for facilitating interdisciplinary research}

Three factors were considered to have affected the character of our cyber Workshop. First, discussions of social aspects were encouraged by the selection criteria of the TTEA, which praised entrepreneurial research aiming to solve social problems or to create economical benefit. Second, discussions of such topics were suitable for applicants from different disciplines because all equally shared the problems as members of society. Third, researchers were eager to discuss because they were interested in subsequent information exchange and collaborative knowledge production to solve problems.

\section{Additional incentive}

A major feature of this TTEA program is that it provides merits not only to the award winner, but also to all applicants. In order to make use of this function, it is critical to attract applicants who will be active participants in the discussion. For this purpose, we have to understand what will serve as incentives for applicants.

One positive factor to increase the merits to applicants is the monetary value of the award. If the award is too small, the applicants will not be willing to spend time participating actively in the cyber workshop. Another positive factor to increase incentive is the adoption ratio. If the adoption ratio is excessively low, the efforts of most of the applicants will not be rewarded, and such an award program is unattractive.

Table 6 shows the adoption ratio of the TTEA (10 million yen - approximately US\$80,000 per year) and other research grants with similar monetary values. The adoption ratio of the Fundamental Research (A) grant-in-aid for scientific research operated by the Japan Society for the Promotion of Science (JSPS) was $22 \%$ (in 2003). The adoption rate of the Grant for Industrial Technology Research operated by National Energy Development Organization (NEDO) was 24\% (in 2003). On the other hand, the adoption ratio of the TTEA was 4\% (in 2002) and 6\% (in 2001). It is clear that the adoption ratio of the TTEA was much lower than for other grants of similar size. Moreover, applicants for the TTEA have to participate in discussions in the cyber workshop during the selection process, with a workload that seemed to be high.

Based on these comparisons, the TTEA seems to be unattractive. However, we should note that over
Table 6. Adoption ratio of research grants of which monetary value was about 10 million yen (approximately US\$80,000) per year

Grants

Adoption ratio

Fundamental Research (A)

(JSPS)

Grant for Industrial Technology 24\% (in 2003)

Research (NEDO)

Takeda Techno-

$4 \%$ (in 2002) and 6\% (in 2001)

Entrepreneurship award (TF)

100 applicants applied both years even though the TTEA provided a low adoption rate and requested a heavy workload. Why were applicants interested in the Takeda Techno-Entrepreneurship Award? We think the review process of the TTEA provided another merit besides the adoption ratio and award money.

In the cyber workshop, comments about other applicants' research proposals and requests for comments about their own research proposals were frequently seen. There were demands for constructive comments and opportunities for learning among applicants. It was considered to be a new merit provided by the TTEA that applicants could satisfy the strong desire to learn and to improve their research proposals. Fortunately, applicants from all over the world (Figure 2) could participate in the discussions in the cyber workshop. These merits may be strong tools to facilitate interdisciplinary research.

\section{Merit of disclosure}

Another important finding was that applicants took the risk of having their ideas stolen. They might take advantage of the opportunity for mutual evaluation.

For the TTEA, it was the research proposals that were disclosed among applicants. This is fundamentally different from the disclosure of completed research at a conference. When we planned the proposal review process, disclosure of the research proposals was criticized as "senseless conduct" by some researchers. The criticism originated with scientists who have intense respect for the first publication of pioneering points or originalities. However, many applicants for the TTEA supported our open proposal review process. In the engineering field, which is the target of the Takeda TechnoEntrepreneurship Award, solving a problem is more important than the first publication. In such fields, although it remains controversial, some researchers may try to find better applications for their technological or experimental innovations by means of disclosure and discussion with other applicants with various points of view. We believe that the proposal review process of the TTEA can serve as a kind of knowledge production in the interdisciplinary research. 


\section{Conclusion}

We introduce a novel research proposal review process to facilitate interdisciplinary research. Our new method was implemented in the proposal review process to select awardees of the Takeda Techno-Entrepreneurship Award. We provided a mutual evaluation opportunity to all applicants via

\section{Notes}

1. In this paper, we use the term "interdisciplinarity" to mean "different disciplines working together and trying to synthesize cognitive approaches", following the definition of EURAB report (2004)

2. Trials of inter- and transdisciplinary research have been performed and their importance and difficulty for assessment have been discussed (eg Thompson Klein et al, 2001; see also the special issue of Science and Public Policy, July 2006, edited and introduced by Maasen, Lengwiler and Guggenheim, and the special issue of Research Evaluation on the assessment of interdisciplinary research, April 2006, edited and introduced by Laudel and Origgi.

3. TTEA is a program designed to praise and encourage researchers through the presentation of an award. See <http:/l www.takeda-foundation.jp/en/award/tech/index.html>, last accessed 10 March 2007.

4. "Sector" means a target issue to be addressed (eg environmental biotechnology, design and development of hardware having flexibility and expandability of functionality and performance, systems aiming at tissue engineering, etc.).

5. The selection committee is a body for the final consideration and approval of the award winners. Chairpersons are assigned by the selection committee and are tasked to explain the core competency of each applied proposal to the Selection committee members.

6. Interactive evaluations are performed in the peer-review processes of collaborative networks in Germany (so-called Sonderforschungsbereiche [since 1968] and Innovationskollegs [1994-2001] financed by Deuche Forschungsgemeinschaft [DFG]). They perform interactive evaluations to fully understand a proposal for interdisciplinary research and to make appropriate decisions concerning grant allocation (Laudel, 2006).

7. For example, directed programs of the Natural Environment Research Council (NERC) < http://www.nerc.ac.uk/research/ programmes/>, last accessed 10 March 2007 (since 1992) or a part of Research Contracts of the National Institute of health (NIH) <http://ocm.od.nih.gov/contracts/contract.htm>, last accessed 10 March 2007 performed a two-stage assessment of proposals. A reviewer assessment was sent to the applicant in the first stage, and a modified proposal or proposer response could be submitted. This was a kind of interactive evaluation, although the review process of other applicants was hidden and communication among applicants was impossible.

8. Seven million yen (approx. US\$58,300) in 2002.

9. Under the Foundation's rules, the selection committee was authorized to select award winners. The chairpersons were the Internet (cyber workshop). Then we selected awardees based on the cyber workshop discussions. This award program succeeded in attracting over 100 applicants from around the world in each year. This suggests that the proposal review process can serve as a kind of knowledge production. Of course it could provide a useful tool for the facilitation of interdisciplinary research. navigators of the cyber workshop and were not authorized to select the award winners.

10. Finalists sent PowerPoint presentations to the Takeda Foundation (TF) in advance of the selection committee interviews. Program officers checked the slides and installed them in the TF computers. Selection committee members met at the TF in a room wired for a conference telephone session. Then each finalist was phoned by a program officer and asked to make a presentation via telephone. Manipulation of the PowerPoint slides was achieved by program officers during the presentation and Q\&A. The PowerPoint slides were changed according to the finalist's order (eg "Next please").

11. The number of comments divided by the number of participants.

\section{References}

Council for Science and Technology Policy, Japan 2005. The Third Science and Technology Basic Plan (FY2006-FY2010), 27 December 2005. <http://www8.cao.go.jp/cstp/english/basic/ index.html\#third>, last accessed 10 March 2007.

EURAB, European Union Research Advisory Board 2004. Interdisciplinarity in Research (EURAB04.009-FINAL), April. <http://ec.europa.eu/research/eurab/pdf/eurab $04 \quad 009$ interdisciplinarity_research_final.pdf>, last accesse $\bar{d} 10 \overline{\text { March }}$ 2007.

Gibbons, Michael, Camille Limoges, Helga Nowotny, Simon Schwartzman, Peter Scott and Martin Trow 1994. The New Production of Knowledge: the Dynamics of Science and Research in Contemporary Societies. London: Sage.

Laudel, Grit 2006. Conclave in the Tower of Babel: how peers review interdisciplinary research proposals, Research Evaluation, 15(1), April, 57-68.

Laudel, Grit and Gloria Origgi eds. 2006. Special issue on the assessment of interdisciplinary research. Research Evaluation, 15(1), April, 1-80.

Maasen, Sabine, Martin Lengwiler and Michael Guggenheim eds. 2006. Special issue on discipline and research: practices of inter-/transdisciplinary cooperation in science. Science and Public Policy, 33(6), July, 393-476.

National Academy of Sciences, National Academy of Engineering, and Institute of Medicine of the National Academies 2005. Facilitating Interdisciplinary Research. Washington DC: National Academies Press.

Thompson Klein, J, W Grossenbacher-Mansuy, R Haberi, A Bill, R W Scholz and M Welti eds. 2001. Transdisciplinarity: Joint Problem Solving among Science, Technology and Society. An Effective Way for Managing Complexity. Basel: Birkhauser Verlag. 2006. Science and Public Policy, 33(9), November. 